\title{
Editor's overview
}

The premier issue of Applied Psycholinguistics

is dedicated to my mother, Antoinette Rosenberg.

in her 80th year, with all my love and respect.

The Editor's overview will be a regular feature of Applied Psycholinguistics (AP). It will serve to integrate the contents of each issue, to keep readers abreast of important developments in the field, and to help make clear the mission and policies of the journal. The aims and scope of AP are detailed on the front cover of each issue. I would draw the reader's attention to three points. First, AP is a comprehensive journal; that is, one that attempts to cover the entire range of problem areas in the field of applied psycholinguistics and to publish empirical, theoretical, methodological and literature review articles. Second, AP publishes articles in which applied problems are approached from the standpoint of basic research and theory in psycholinguistics and related areas of cognitive psychology. Thus, it is essential that authors make explicit the basic underpinnings of their work in the manuscripts they submit to the journal. Third, we are interested in publishing not only narrowly focused papers, but ones which recognize the essential interrelations between the various sub-areas of applied psycholinguistics; for example that recognize the contribution that second-language intervention procedures might make to the development of first-language training programs for mentally retarded or aphasic children, or the contribution that an understanding of reading and writing processes in hearing children might make to our understanding of the problems profoundly deaf children have developing literacy.

AP is a rigorously refereed scientific journal that publishes original high quality articles that make a significant contribution to the literature. The rejection rate on articles processed for this issue was 71 percent. Present in the articles we rejected were combinations of such problems as limited contribution to the literature; absence of theoretical sophistication; methodological unsoundness; failure to supply an acceptable rationale for predictions; problems of data analysis; poor writing style; lack of knowledge of relevant applied and/or basic literature; failure to obtain important information regarding subject characteristics; duplication of a previously published article; uncritical, nonintegrative or unfocused reviews of literature; absence of a relationship between the statement of purpose of a study and its design; and absence of a relationship between the findings of a study and their interpretation.

- 1980 Cambridge University Press 0142-7164/80/010001-05\$02.50 


\section{HISTORY}

We in the editorial office have received so many inquiries regarding the journal and so many unsolicited expressions of support that I thought readers would be interested in highlights of the history of its creation.

In 1968, James H. Koplin and I co-edited a small book of papers from a summer institute in applied psycholinguistics that contained an introduction and an overview in which we attempted (albeit briefly) to characterize and integrate the work in this field and to identify its major empirical and theoretical thrusts from the standpoint of relevant basic research and theory. We were convinced, even during the early years of the "Chomskian revolution" that this work had a serious contribution to make to applied problems. However, when I returned to this field in 1978 to develop new course work with my colleague David Fay, and a program of applied research (after several years of basic research activity), I was surprised to find that although there had been significant developments in a number of the sub-areas of applied psycholinguistics, some work was still being carried out along traditional disciplinary lines, available textual material was limited in scope and generally uncritical, and articles that were written from a basic research and theory vantage point were spread throughout well over 40 journals in the English language alone and varied considerably in quality. The major refereed journals that were publishing applied psycholinguistic work (as herein defined) were either limited in scope (i.e., to one particular sub-area or to just a few of the sub-areas of this field) or interested in publishing mainly basic research and theory oriented articles.

Clearly, one of the things that was missing from the field of applied psycholinguistics was a comprehensive, multidisciplinary and international journal dedicated to publishing the high quality articles of workers who approach applied problems from the standpoint of basic research and theory in psycholinguistics and related areas of cognitive psychology.

As soon as I became convinced of the need for such a journal, I corresponded with my good friend and frequent adviser, Lawrence Erlbaum, publisher of a distinguished library of professional books in psychology, on the matter. His reaction was immediate and positive: he encouraged me to proceed to explore with a number of publishers the idea that resulted eventually in the creation of the present journal. I then approached a large number of the major contributors to the fields of basic and applied psycholinguistics (and related fields as well) with the same idea and was gratified to find that they all agreed that there was a strong need for a periodical that would give shape and continuity to the notion of a basic research and theory oriented applied psycholinguistics. Indeed, it was clear from the responses I received to my letters that such a journal was on the minds of many scientists.

Armed with the support I have just described and agreements from a number of the scientists I had asked to serve on the editorial board of the proposed journal, I prepared a formal prospectus for the journal and submitted it to a number of publishers. There followed several months of continuous 
negotiations that produced, finally, four offers to publish the journal. It was determined, however, in the final analysis, that only Cambridge University Press met all of the criteria that had been set up for evaluating prospective publishers.

\section{ACKNOWLEDGEMENTS}

Many factors combined to create AP and this, its first issue. I would like to cite in particular the dedication and excellence of Cambridge University Press-New York's Journals Editorial and Promotion Manager, Sue Potter, Behavioral Sciences Editor, Susan Milmoe, and their colleagues Andrée Lockwood and Blaise Miller; the sage advice I received from Lawrence Erlbaum; the willingness of an already overworked group of leading scientists from the fields of education (including special education), linguistics, neurology, psychiatry, psychology and speech and hearing to accept still another professional responsibility, that of Consulting Editors on a new journal; the important contribution of our guest referees on the first issue (the final issue of each volume of AP will contain the names of our guest referees); the first-rate secretarial assistance $I$ have received locally from Jacqueline Erickson; the many helpful suggestions of my colleague Leonard Eron, Editor of the Journal of Abnormal Psychology, and his assistant Susan Vaitkus on how to set up and operate a journal editorial office; the local resources that are made available for the professional development of faculty; the kind assistance of the administrative supervisor of the Department of Psychology of The University of Illinois at Chicago Circle, Joyce Rozwadowski; and the encouragement and emotional support I have received from my family.

I am deeply grateful to all the individuals, named and unnamed, who have been associated, officially or unofficially, with this project, not only for what their contributions mean to me personally, but for what I believe they have done to advance the field of applied psycholinguistics.

\section{VOLUME 1, NUMBER 1}

Three of the articles in the present issue address, directly (Stoel-Gammon, Tallal et al.) or indirectly (Leonard, Newhoff \& Mesalam), questions concerning disorders of language development in the realm of phonology. Leonard et al.'s article is concerned indirectly with such disorders in the sense that determining the nature, range, and origin of individual differences in normal phonology is a prerequisite for studying phonological disorders in language impaired children. A feature of individual differences in child phonology that I found interesting, in relation to the question of individual differences in language acquisition strategies (Nelson, 1973), was their appearance early in language development.

The differences in language development investigators have observed between mentally retarded (including Down's syndrome) children and their 
chronological age- and mental age-matched nonretarded counterparts appear to have been quantitative rather than qualitative regardless of whether syntax, semantics, or phonology was being scrutinized. StoelGammon reports findings consistent with this trend in a more extensive study than has heretofore been published of phonological production in Down's syndrome children. Moreover, when retarded/nonretarded comparisons were carried out in this investigation with matching on the basis of mean length of utterance (an estimate of overall linguistic maturity during the early stages of language acquisition), there was no evidence of developmental lag in her Down's sample.

The studies I have just discussed, and others, on phonological production are complimented by the program of research of Tallal and her associates which has centered on studying the psycholinguistic and information processing characteristics of speech-sound perception in language delayed children with normal performance IQs. The work of these investigators that appears in the present issue of AP suggests, at least in the case of normal children, that speech-sound perceptual performance "changes throughout language development."

The study by Greenberg of profoundly deaf children in whom the disorder "occurred prior to language acquisition" reflects the current basic and applied interest in the acquisition of communicative, as opposed to syntactic, phonological, morphological, lexical-semantic, and propositional-semantic capabilities. Greenberg's study revealed a complex set of interactions involving communication method, mode use, the communicative function of a message, speech intelligibility, and a deaf child's level of communicative competence that has important implications for speech and manual-language education in the deaf.

I had occasion recently to read a large segment of the literature on adult schizophrenic language and communication and to examine samples of what was considered to be disturbed speech, and found, as others had previously, evidence of disturbed thinking but no hard evidence of linguistic (i.e., syntactic, morphological, phonological) deviance. Furthermore, I did not find that the discourse of adult schizophrenics was less cohesive than it needed to be given what they appeared to be trying to say semantically and pragmatically, or that their speech was developmentally regressed or disturbed any more than a small proportion of the time. Finally, I could find nothing to indicate that adult schizophrenics have special difficulties comprehending normal speech.

Against these observations one has to pit the findings of the case study by Herbert and Waltensperger in the present issue of a paranoid-type chronic schizophrenic male who evidenced a higher than average incidence of disturbed speech and writing as well as some uncommon (to schizophrenics) types of disturbed production. However, as these authors are quick to point out, what characterizes the speech and writing of this patient may be a reflection of both a schizophrenic psychopathology and neurological impairment. 
Psycholinguists and others have recognized that the linguistic and communicative competencies of normal children can continue to grow during the elementary school years and beyond, as reflected in the development of (1) the complex lexical items and sentential and discourse structures of the native language, (2) metalinguistic awareness, (3) reading, (4) writing, and (in some children) (5) a non-native language. Moreover, there is increasingly an awareness in the literature (e.g., Ingram, 1975; Donaldson, 1978; Lundberg, 1978; Olson \& Nickerson, 1978) of the possibility that there exist, on the one hand, interdependencies among these various aspects of mature linguistic and communicative competence, and, on the other hand, interdependencies between aspects of linguistic and communicative maturity and cognitive development generally. This brings us to the last two papers in the present issue of AP, for in the case of one of them (Genesee \& Hamayan), there was an interest in the relationship between young school children's progress in second-language learning and, among other things, cognitive style (e.g., field independence), and in the other (Kagan), an interest in the relationship between the syntactic complexity of secondary and post-secondary students' writing and such measures of cognitive style as field independence. What I found interesting was the observation that the cognitive analyticity of field independence was positively related to certain achievements of second-language learning in the study by Genesee and Hamayan and to "the ability to manipulate language effectively" in the service of writing in the research of Kagan.

\section{REFERENCES}

Donaldson, M. Children's minds. Glasgow: Fontana/Collins, 1978.

Ingram, D. If and when transformations are acquired by children. In M.P. Dato (Ed.), Developmental psycholinguistics: Theory and applications. Washington, D.C.: Georgetown University Press, 1975.

Lundberg, I. Aspects of linguistic awareness related to reading. In A. Sinclair, R.J. Jarvella and W.J.M. Levelt (Eds.), The child's conception of language. Berlin: Springer-Verlag, 1978.

Nelson, K. Structure and strategy in learning to talk. Monographs of the Society for Research in Child Development, 1973, 38 (1-2, Serial number 149).

Olson, D.R., \& Nickerson, N. Language development through the school years: Learning to confine interpretation to the information in the text. In K.E. Nelson (Ed.), Children's language, Volume 1. New York: Gardner Press, 1978.

Rosenberg, S., \& Koplin, J.H. (Eds.), Developments in applied psycholinguistics research. New York: Macmillan, 1968.

\section{SHELDON ROSENBERG}

Chicago, Illinois

November 1979 